\title{
RIESGO DE INCENDIOS A PARTIR DEL ANÁLISIS ESPACIAL DE PENDIENTES Y DE COMBUSTIBILIDAD POR USO DEL SUELO, EN LAS VEREDAS COLINDANTES CON LA ZONA URBANA DE AGUACHICA, CESAR
}

\author{
RISK OF FIRES FROM THE SPACE ANALYSIS OF SLOPES AND \\ COMBUSTIBILITY FOR USE OF THE SOIL, OF FIRE OF RURAL ZONE \\ CONTRIBUTORS WITH THE URBAN AREA OF AGUACHICA, CESAR
}

\author{
MSc. Juan Carlos Hernández Criado*, Ing. Juan David Herrera Galviz* \\ Ing. Kevin Andrés Otalvaro Valencia*** \\ * Universidad Francisco de Paula Santander Ocaña, Facultad de Ciencias Agrarias y del \\ Ambiente, Grupo de Investigación GI@DS. \\ Vía Acolsure, Sede El Algodonal, Ocaña, Norte de Santander, Colombia. \\ Teléfono: (7) 5690088 ext 449. \\ E-mail: $\{$ jchernandezc, jdherrerag $\} @$ ufpso.edu.co. \\ ${ }^{* *}$ Universidad Francisco de Paula Santander Ocaña, Egresado del programa de \\ Ingeniería Ambiental. \\ Aguachica, Cesar, Colombia. \\ E-mail: kaotalvarov@gmail.com.
}

\begin{abstract}
Resumen: Este trabajo presenta los resultados de un índice espacial de riesgo de incendios de las veredas que colindan con la zona urbana del municipio de Aguachica Cesar. Para calcular este riesgo, se determinó primero los índices de riesgo por pendiente y por combustibilidad por uso del suelo, empleando tecnologías de la información geográfica. Se obtuvo que la categoría de riesgo prevaleciente en la zona de estudio, corresponde al riesgo moderado, seguido del riego bajo, sin embargo, se evidencia riesgo alto al nororiente de dicha zona de estudio. Por consiguiente, se hace necesario enfocar acciones hacía estas áreas con el fin de minimizar el riesgo de incendios forestales.
\end{abstract}

Palabras clave: Incendios Forestales, Riesgo por pendiente, Combustibilidad, Tecnologías de la información geográfica.

\begin{abstract}
This paper presents the results of a spatial index of risk of fires of the sidewalks that adjoin the urban area of the municipality of Aguachica Cesar. In order to calculate this risk, the risk indexes for slope and combustibility for land use were first determined, using geographic information technologies. It was obtained that the risk category prevailing in the study area corresponds to moderate risk, followed by low risk, however, there is high risk to the northeast of said study area. Therefore, it is necessary to focus actions towards these areas in order to minimize the risk of forest fires.
\end{abstract}

Keywords: Forest Fires, Slope Risk, Combustibility, Geographic Information Technologies. 


\section{INTRODUCCIÓN}

Los incendios son eventos que impactan los ecosistemas donde existe presencia de masas de vegetación, los cuales se encuentran por lo general en las zonas rurales, generando efectos sobre los usos del suelo y los paisajes y sobre la estabilidad ecosistémica de extensas áreas de bosque, que a su vez repercute en las dinámicas socioeconómicas del territorio, ya que aunque existen incendios de causa natural, en general la mayor parte de los incendios son por causas antrópicas (Moreno et al., 2015). En Colombia, uno de los ecosistemas que más afecta es el Bosque Seco Tropical, ecosistema del cual se conserva muy poca área con respecto a su área inicial en el país (Instituto Humboldt, 2014) (RJG Amaya, OAC Campos. 2017).

De acuerdo a lo anterior, los incendios forestales son considerados un tipo de evento susceptible de zonificación de riesgo (Congreso de la República, 2012), teniendo en cuenta que el riesgo representa la probabilidad de que se presente un conjunto de consecuencias socioeconómicas y ambientales a partir de un evento adverso natural o antrópico (IDEAM, 2011).

Así, hoy día se utilizan las tecnologías de la información geográfica como herramientas que permiten fácilmente la captura de la información inicial que permite evaluar este riesgo (MorenoRuiz et al., 2014) (Bisquert et al., 2010) (Chuvieco y Pettinari, 2015).

El trabajo presentado en este documento corresponde entonces a un análisis espacial de riesgo de incendios forestales para las 6 veredas aledañas al casco urbano del municipio de Aguachica - Cesar las cuales son: el crisol, las clavellinas, sabanas de buturama, sabanas del corral, gallinazo, sabanas de lázaro y el guaro. En este sentido se estableció como objetivo trabajar con riesgo de incendios forestales, debido a la ocurrencia de estos eventos en dichas áreas, a la ausencia de estudios de riesgos en las mismas, y a la presencia de ecosistema de bosque seco en zonas de estas veredas. (JEM Gutierrez, RC Hernández. 2017).

\section{METODOLOGÍA}

El cálculo de este índice de riesgo, se realiza a partir de calcular los índices de riesgo por pendiente y el índice de combustibilidad por uso del suelo, empleando la metodología propuesta por Noriega (2016). Para el caso del primer índice, se empleó la información de altitud. Esta información se obtuvo a partir de la descarga de un modelo digital de elevación (DEM en inglés) de 12,5 m de resolución el píxel. A partir de este DEM, se realizó el mapa de pendiente respectivo usando la herramienta Slope de ArcGIS. El mapa de pendiente obtenido se sometió a reclasificación para asignar las siguientes categorías:

\section{Tabla 1: Categorías de riesgo orográfico}

\begin{tabular}{ccc}
\hline Pendiente \% & $\begin{array}{c}\text { Nivel de } \\
\text { Riesgo }\end{array}$ & $\begin{array}{c}\text { Valor del } \\
\text { Índice }\end{array}$ \\
\hline$<5$ & Muy Bajo & 1 \\
$5-<25$ & Bajo & 2 \\
$25-<35$ & Medio & 3 \\
$35-<55$ & Alto & 4 \\
$>=55$ & Muy Alto & 5 \\
\hline
\end{tabular}

Fuente: Noriega (2016)

Posteriormente, se gestionó una imagen satelital del proyecto Sentinel 2A, en la cual se empleó el método de clasificación supervisada para obtener polígonos que representan 6 clases de uso del suelo, que son: suelo desnudo o edificado, pecuario y pastos limpios, zona agrícola, matorral y vegetación, leñosa y masas forestales. Estos polígonos fueron corroborados en campo mediante salidas y captura de puntos de control. Con el mapa de usos del suelo consolidado, se procedió a aplicar el criterio del índice de combustibilidad por uso del suelo teniendo en cuenta lo referenciado en la tabla 2:

Tabla 2: Categorías de riesgo por combustibilidad

\begin{tabular}{ccc}
\hline $\begin{array}{c}\text { USO DEL } \\
\text { SUELO } \\
\text { (Combustible } \\
\text { Vegetal) }\end{array}$ & $\begin{array}{c}\text { Nivel de } \\
\text { Riesgo }\end{array}$ & $\begin{array}{c}\text { Valor del } \\
\text { Índice }\end{array}$ \\
\hline $\begin{array}{c}\text { Suelo Desnudo o } \\
\text { Edificado }\end{array}$ & Muy Bajo & 1 \\
$\begin{array}{c}\text { Pecuario, Pastos } \\
\text { limpios }\end{array}$ & Bajo & 2 \\
$\begin{array}{c}\text { Zona Agrícola } \\
\text { Matorral y }\end{array}$ & Medio & 3 \\
Vegetación Leñosa & Alto & 4 \\
Masas Forestales & Muy Alto & 5 \\
\hline
\end{tabular}

Fuente: Noriega (2016).

Por último, se utilizaron los dos mapas anteriores, empleando el álgebra de mapas, para sumar los valores asignados en el campo Valor del Índice, de cada shapefile. El mapa obtenido, se clasificó de acuerdo al criterio de la tabla 3 : 
Tabla 3: Riesgo Consolidado

\begin{tabular}{llll}
\hline $\begin{array}{l}\text { Rango } \\
\text { valores }\end{array}$ & de & Índice & $\begin{array}{l}\text { Riesgo de } \\
\text { Incendios }\end{array}$ \\
\hline $1-2$ & 1 & Muy Bajo \\
$3-4$ & 2 & Bajo \\
$5-6$ & 3 & Medio \\
$7-8$ & 4 & Alto \\
$9-10$ & 5 & Muy Alto \\
\hline
\end{tabular}

Fuente: Noriega (2016).

\section{RESULTADOS Y DISCUSIÓN}

A partir del primer proceso, se obtuvo el mapa de pendientes del área de estudio. Dicha área de estudio corresponde a 6 veredas que colindan con el área urbana del municipio de Aguachica en el cesar. El mapa de pendientes se puede visualizar en la figura 1.

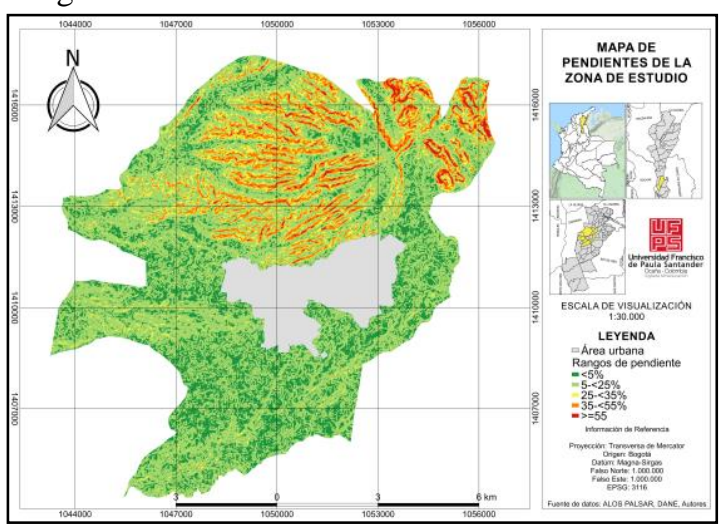

Fig. 1. Mapa de pendientes. Fuente: Elaboración propia

Ese mapa de pendientes se tradujo a un mapa de riesgo orográfico, usando el criterio dispuesto en la tabla 1. El mapa de riesgo por pendiente se puede visualizar en la figura 2 .

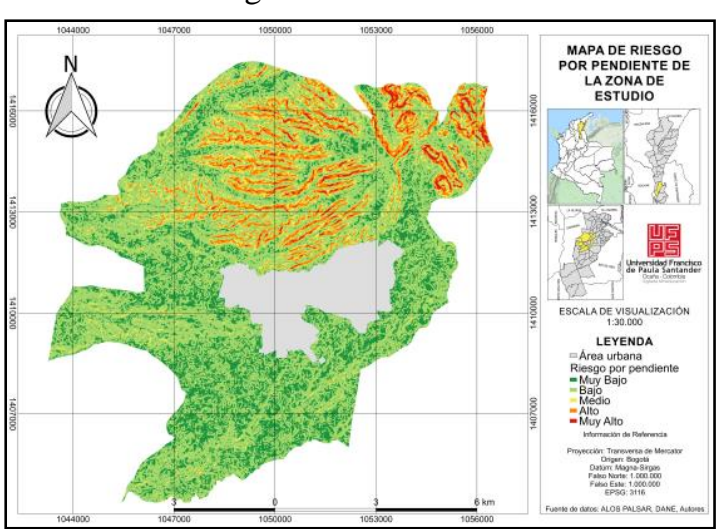

Fig. 2. Mapa de riesgo por pendiente. Fuente: Elaboración propia

A partir de este mapa, se obtuvo las áreas por zona de riesgo que se relacionan en la tabla 4 , donde se evidencia que existe un riesgo bajo en gran parte del área de estudio, debido a que el relieve en esta zona del país, es de tipo planicie en su mayor parte. Solo se evidencia riesgo alto y muy alto hacía la zona norte y noreste del área de estudio, que se aproxima a la cordillera oriental en límites con el departamento de Norte de Santander.

\section{Tabla 4: Áreas por Zonas de Riego Orográfico}

\begin{tabular}{cc}
\hline Nivel de Riesgo & Área (Ha) \\
\hline Muy Bajo & 2058,3 \\
Bajo & 5270,5 \\
Moderado & 816 \\
Alto & 814,9 \\
Muy Alto & 162,6 \\
\hline
\end{tabular}

En la segunda fase del trabajo, se obtuvo el mapa

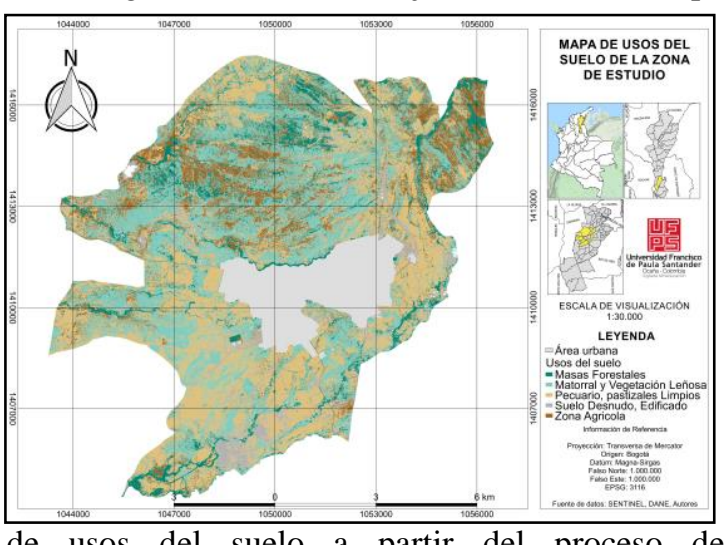

de usos del suelo a partir del proceso de clasificación supervisada, el cual se evidencia en la figura 3.

Fig. 3. Mapa de usos del suelo. Fuente: Elaboración propia.

De dicho mapa, se obtuvo el mapa de riesgo por combustibilidad por usos del suelo, aplicando el criterio de la tabla 2. Este mapa se puede evidenciar en la figura 4. 


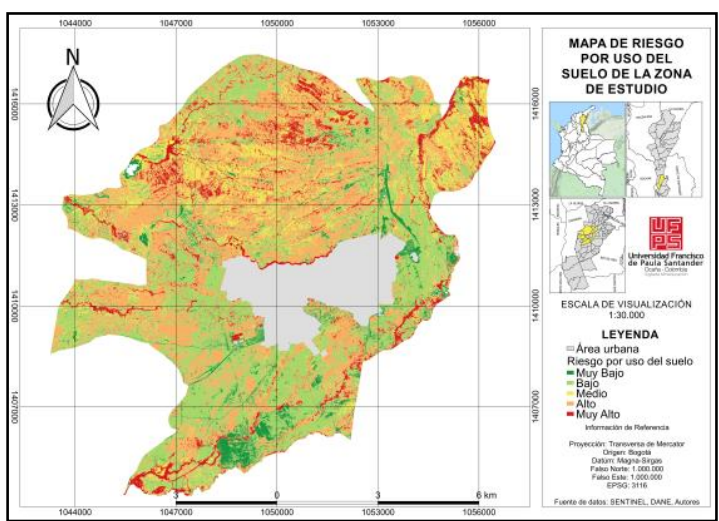

Fig. 4. Mapa de riesgo por combustibilidad. Fuente: Elaboración propia

Este mapa, permitió calcular áreas por zona de riesgo que se evidencian en la tabla 5. De dicha tabla se infiere que las zonas de riesgo alto son las que mayor representatividad en área tiene, debido a la presencia de matorrales y vegetación leñosa que prevalece en dicha zona de estudio.

\section{Tabla 5: Áreas por Zonas de Riego por combustibilidad}

\begin{tabular}{cc}
\hline Nivel de Riesgo & Área (ha) \\
\hline Muy Bajo & 622,3 \\
Bajo & 2852,4 \\
Moderado & 1510,3 \\
Alto & 3223,5 \\
Muy Alto & 864,9 \\
\hline
\end{tabular}

Por último se obtuvo el resultado del proceso efectuado en el álgebra de mapas, usando los mapas de riesgo orográfico y por combustibilidad. Dicho resultado se evidencia en la figura 5.

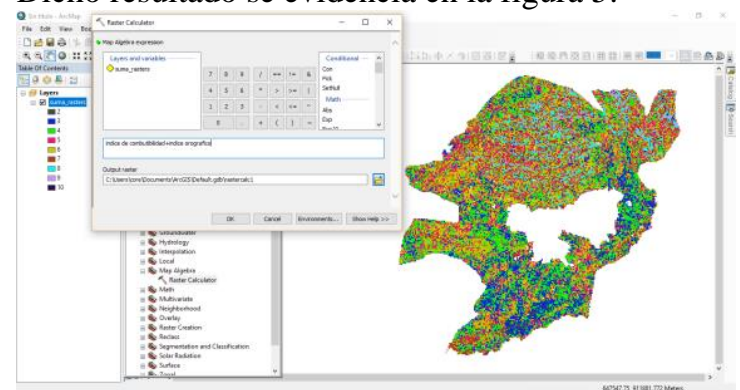

Fig. 5. Resultado del proceso en el álgebra de mapas. Fuente: Elaboración propia.

Y a dicho resultado se le aplicó el criterio de la tabla 3, para obtener el mapa de riesgo consolidado de incendios forestales que se evidencia en la figura 6 .

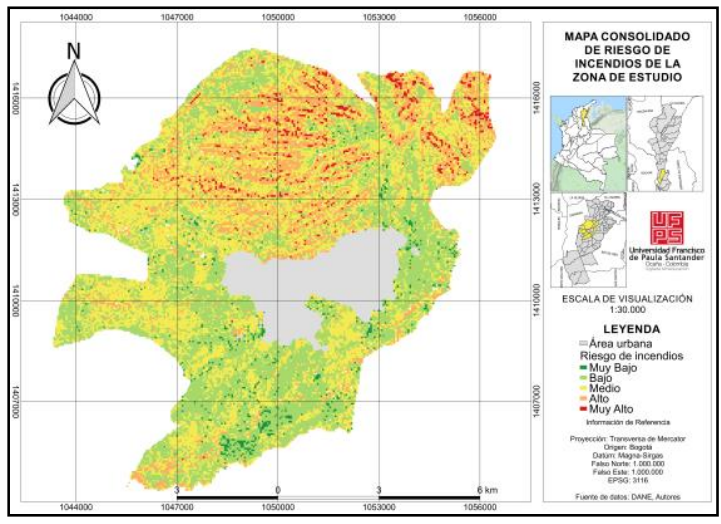

Fig. 6. Mapa de riesgo consolidado de incendios. Fuente: Elaboración propia.

A partir de este mapa se calcularon las áreas por zonas de riesgo, que se evidencian en la tabla 6 .

Tabla 6: Áreas por Zonas de Riego Total

\begin{tabular}{cc}
\hline Nivel de Riesgo & Área (ha) \\
\hline Muy Bajo & 181,5 \\
Bajo & 3231,8 \\
Moderado & 3766,4 \\
Alto & 1599 \\
Muy Alto & 204,9 \\
\hline
\end{tabular}

De lo anterior, se puede inferir que la mayor parte del área de estudio se encuentra en riesgo moderado y bajo, influenciado por el bajo riesgo por pendiente que prevalece en dicha zona. Sin embargo, es importante enfocar acciones de reducción del riesgo en las zonas categorizadas en riesgo alto y muy alto ubicadas hacía el nororiente de la zona de estudio.

\section{CONCLUSIONES}

El riesgo territorial por incendios forestales en la zona rural que colinda con la zona urbana del municipio de Aguachica - Cesar se caracteriza por ser en gran parte riesgo moderado - bajo, con algunas zonas de riesgo alto y muy alto principalmente ubicadas en las veredas sabanas de buturama y el guaro, influenciadas en gran parte por la presencia de vegetación leñosa en zonas con relieve tendiente a montañoso. Por consiguiente, es necesario enfocar acción de reducción del riesgo en estas dos veredas.

\section{REFERENCIAS}


Bisquert, M., Sánchez, J. M., Caselles, V., PazAndrade, M. I., \& Legido, J. L. (2010). Los índices de vegetación como indicadores del riesgo de incendio con imágenes del sensor TERRA-MODIS. (A. E. Teledetección, Ed.) Revista de Teledetección, 33, 80-91. http://www.aet.org.es/revistas/revista33/N umero33_8.pdf (Consultado el 10 de septiembre de 2018)

Chuvieco, E., \& Pettinari, M. L. (2015). Cartografía de combustible y potenciales de incendio en el continente africano utilizando FCCS. (A. E. Teledetección, Ed.) Revista de Teledetección, 43, 1-10. http://polipapers.upv.es/index.php/raet/arti cle/view/2302/4091 (Consultado el 10 de septiembre de 2018)

Congreso de la República. (2012). Ley 1523. Por la cual se adopta la política nacional de gestión del riesgo de desastres y se establece el Sistema Nacional de Gestión del Riesgo de Desastres y se dictan otras disposiciones.

http://www.alcaldiabogota.gov.co/sisjur/n ormas/Norma1.jsp?i=47141 (Consultado el 10 de septiembre de 2018)

Instituto de Hidrología Meteorología y Estudios Ambientales. (2011). Protocolo para la realización de mapas de zonificación de riesgos a incendios de la Cobertura Vegetal Escala 1:100.00. Bogotá D.C.: IDEAM.

Instituto de Investigación de Recursos Biológicos Alexander Von Humboldt. (2014). El Bosque Seco Tropical en Colombia. (C. Pizano, \& H. García, Edits.) Bogotá D. C., Colombia.

JEM Gutierrez, RC Hernández. (2017). Modelo No Lineal Para Análisis De La Interacción Suelocimiento Revista Colombiana de Tecnologías de Avanzada ISSN: 16927257.

Moreno-Ruiz , J. A., Arbelo, M., García-Lázaro, J. R., \& Riaño-Arribas, D. (2014). Desarrollo de una metodología para la detección de cambios de la cubierta vegetal en series temporales de imágenes de satélite diarias. Aplicación a la detección de áreas quemadas. (A. E. Teledetección, Ed.) Revista de
Teledetección, $\quad 42, \quad 11-28$. http://polipapers.upv.es/index.php/raet/arti cle/view/2280/3672 (Consultado $10 \mathrm{de}$ septiembre de 2018)

Moreno, J. M., Urbieta, I. R., Bedia, J., Gutiérrez, J. M., \& Vallejo, V. R. (2015). Los incendios forestales en España ante al cambio climático. http://80.24.165.149/webproduccion/PDFs /15CAP03.PDF (Consultado $10 \mathrm{de}$ septiembre de 2018)

Noriega, A. (2016). Estimación del Índice de Riesgo Territorial de Incendio. Retrieved from http://www.cursosgis.com/estimacion-delindice-de-riesgo-territorial-de-incendiocon-arcgis (Consultado el 10 de septiembre de 2018)

RJG Amaya, OAC Campos. (2017), Análisis Del Comportamiento De Suelos De Alta Plasticidad Con La Adición Del Material De Residuo En La Fabricación De Ladrillo. Revista Colombiana de Tecnologías de Avanzada ISSN: 16927257. 